\title{
Questioning Assumptions about Race, Social Class and Crime Portrayal: An Analysis of Ten Years of Law and Order
}

\author{
Patricia Case*
}

\author{
Department of Sociology and Anthropology, The University of Toledo, 2801 W. Bancroft, MS 956, Toledo, OH \\ 43606, USA
}

\begin{abstract}
Social researchers have paid significant interest to the portrayal of non-whites and members of the lower classes in both news broadcasts and the fictional crime drama. They have also explored whether social programming uses educational entertainment to positively sway public opinion or as propaganda to support the status quo. Little has been done recently to determine the representation of intra- versus interracial crime in the crime drama. Also, there is the underlying assumption that may be taken almost a priori by viewers that criminals are more often portrayed as poor and non-white and victims are more often portrayed as whites with more resources. This study utilizes the first ten year of Law and Order, an immensely successful crime drama. It explores both the portrayal of victims and perpetrators by race and social class as well as an examination of how these topics are framed and communicated to the public. Descriptive statistics are used to determine whether the portrayal by race and social class is reflective of crime rates during the decades. A content analysis is used to determine if topics that deal specifically with these factors are designed to educate, maintain the status quo, or perhaps accomplish both goals.
\end{abstract}

Keywords: Crime, crime drama, race, social class, public opinion.

\section{INTRODUCTION}

The role that the media plays in supporting and creating social beliefs and stereotypes has been studied frequently by social scientists (Surette, 1998; Dixon and Linz, 2000; Eschholz, Mallard and Flynn, 2004). This is especially true of news sources, both print and televised. These past studies have shown that the representation of crime, especially violent crime, in the media has increased fear in the citizenry and given us an unrealistic understanding of the nature of crime and deviance in the real world. The media is viewed as one of the driving forces in our understanding of crime in public opinion and, according to Surette (2007) it is impossible to understand public opinion about crime without taking the role of the media into consideration because the two are intrinsically connected. Furthermore, there is a debate over whether responsible programming should be a goal of broadcasts on crime (Klein, 2010) and whether socially responsible reporting or portrayals would diminish the popularity and ratings, and thereby income, for programs that attempt to engage this philosophy.

This study was designed to determine if our assumptions about the crime drama hold true in current popular television. I examine the portrayal of race and social class as it has been portrayed in Law and Order, an immensely popular television crime drama. This paper will discuss not only the portrayals of victims and

*Address correspondence to this author at the Department of Sociology and Anthropology, The University of Toledo, 2801 W. Bancroft, MS 956, Toledo, OH 43606, USA; Tel: 419-530-4665; Fax: 419-530-8406;

E-mail: Patricia.Case@utoledo.edu perpetrators by race, but also whether the portrayal of interracial vs. intraracial crime is realistic. I also explore the use of realistic and educational topics in the series and how those topics are presented. Finally, I explore whether the portrayal of crime by social class is realistic. This study contributes to the research discussion on crime and the media that is currently being undertaken in most Western cultures.

\section{LITERATURE REVIEW}

Eschholz and colleagues (2004) used the first season of Law and Order in a study of how images or race are portrayed in the crime drama. They wrote "While news portrayals are not the emphasis of the present study, we consider these findings in our literature review because of the tendency of both news agencies and drama producers to blur the lines between news and entertainment (2004:164)." Although this study utilizes only fictional programming, I will also use this approach to summarizing the literature that examines the representation of race and class in news programming.

There is a plethora of research on crime in the media that dates back several decades. Regardless of the era of publication, past research on the topic of the media and crime is divided into two frameworks; understanding the way that news is reported and understanding the role that the crime drama plays. We have come to expect that race and social class are important predictors for the way that crime is reported as well as the way that criminals and victims are portrayed in the media. We may accept, almost a priori, 
that the victims will typically be portrayed as white and the victimizers will typically be non-white. In fact, even when the representations of race and crime reflect the actual crime statistics, the public reports that blacks are more often portrayed as criminals (Eschholl et al., 2004). We may also tend to expect that most criminals will be non-white males and come from a poor or working class background, though recent studies suggest that our assumptions on race and class may need to be revised (Mastroa, and Robinson, 2000; Schildkraut, and Donley, 2012). Finally, we expect that the criminal justice system will be negatively portrayed in the press and in popular entertainment (Cheatwood, 2010) and that research has shown that the media focuses on maintaining the status-quo over educating the population (Delli Carpini and Williams, 1994).

\section{The Importance of the Media in Framing Public Opinion}

Social scientists have been studying the relationship between crime and the media for decades, especially as it relates to violent crime and race. In an oft sited study of 3000 American films from the 1950s, George Gerbner found that roughly $66 \%$ of those films had violent content. By the late sixties, violence accounted for approximately $80 \%$ of film content (Reber and Chang, 2000; Gerbner and Gross, 1970). Crime also dominates the majority of news programs with $20-50 \%$ of news reports focusing on violent crime since the early nineties (Klite, Bardwell and Salzman, 1997; Artwick and Gordon, 1998). The use of violence in both the news and entertainment has not changed since we began to study it. In fact, the use of violent crime to 'sell' appears to be normalized within the media. Gilliam (2000) argued that both the news (print and televised) and the crime drama operate with a 'script'; an expected progression of events that he likened to eating out and expecting to pay after your meal. This 'script' is driven by societal norms as much as it reinforces those norms. The three elements of that script are that crime is violent, coverage focuses on discrete events rather than general outcomes and we are delivered a 'prime suspect', most often identified by his or her race/ethnicity. He argued that this reinforces the notion that crime is a function of race and or ethnicity in public opinion (Gilliam, 2000).

The relationship between race and violent crime is extremely important to note. Randall and colleagues (1988) argued that the general public "relies on the media for information about the nature, likelihood, and distribution of crime" (Randall, Lee-Sammons and
Hagner, 1988). Meyer (1975) argued that individuals use the media representations of crime to develop their understanding of the reality of crime. Since few of us actually experience crime firsthand, the media's portrayal of crime may become our 'blueprint' for understanding criminal motivations and actions. This finding has not changed in nearly two decades. Greer (2005) also argued that the public is constantly bombarded with images of violent crime, when in fact most people will never be the victim of a violent crime. This remains true even when actual crime rates fall. These images of violent crime occur in both the news media and in our popular programming. Furthermore, they are present not only in the United States, but in most Western societies. The consequence of this exposure is that viewers are left believing that their society is significantly more violent than it actually is which leads to unnecessary fear in society. Also, the emphasis on crime reporting and crime dramas means that the majority of individuals will get all of their "knowledge" of the criminal justice system from misleading sources (Klein, 2011). To add to this misunderstanding of crime and society, Feilzer (2009) found that academic research and data from national statistics does little to reduce the media's misrepresentation of crime or the belief in incompetence in the justice system. This leaves us with a population that is exposed to a lot of information on crime and society with little understanding of the social facts associated with crime.

Along with increasing individual fear and creating 'false knowledge', some argue that this misrepresentation of crime can lead to a more punitive criminal justice system and more state control (Boda, and Szabó, 2011). Since most people are not personally victims of crime, it is argued that we develop our opinions about crime from media exposure (Cheatwood, 2010; Littlefield, 2011) and these public opinions, which are based on a false understanding of crime drive public policy and the creation of laws. Furthermore, the media representation of crime has been linked to agenda setting for political action as well as a means for critiquing and/or creating an attitude of distrust or incompetence in the criminal justice system (Holbrook, and Hill, 2005; Cheatwood, 2010). This finding has also been stable over the years. Valentino (1999) made this argument as well. He argued that the media influences what we think about and how we frame those thoughts. Furthermore, he argued that the media 'primes' our understanding of race and crime, especially during election years, with the use of stereotyping. Simmel (1908) is likely the first to make 
note of the use of stereotyping to form social opinions. He wrote:

The picture that a man gains of another man through personal contact with him is based on certain distortions. These are not simple mistakes resulting from incomplete experiences, defective vision or sympathetic or antipathetic prejudices. They are fundamental changes in the actual quality of the object perceived, and they are of two types. We see the other person generalized in some measure (p.9). In order to know a man, we see him not in terms of his pure individuality, but carried, lifted up or lowered by the general type under which we classify him. (Simmel, 1908:10 in Levine, 1971).

Valentino argues that the natural instinct is to classify individuals via our prejudices and that it takes an active cognitive effort to distance ourselves from stereotyping. The media, whether intentionally or unintentionally, reinforces those stereotypes and primes a racist or stereotypical understanding of social issues (Valentino, 1999).

Robinson (2000) argued that the media both constructs and reinforces a mythology about crime, especially as it pertains to the race and social class of the criminal. He argues that "crime myths are built around particular groups in society, usually lower-class, minority males." This leads to a fear and distrust of minorities, especially males, that is not restricted to the white population. Furthermore, this mythology supports three false assumptions; crime is what is worst for society, African Americans are more often criminals, and the justice system is fair (Robinson, 2000: 133).

Not all research argues that the media informs public opinion on crime. Mason (2006) found in a study of British media reports on prisons that the motivating factor behind policy was the relationship between the government and the media rather than the public. However, it is clear in the United States that the "tough on crime" campaign strategy is often used by prosecutors, judges and politicians alike (Swisher, 2010) It would seem that the link between government participation and voter participation would mean that public opinion does influence the system in the United States, though it may be an indirect relationship. In fact, Boda and Szabó (2010) argue that the influence of the media on public opinion is indirect and only one of the many factors that we filter to create our perception of the world.

While we understand that popular media and public opinion are intrinsically linked, it is impossible to determine how much the media influences opinion versus reflects societal expectations for group behavior. Eschholz and colleagues (2004) argue that when fictional programs borrow storylines from the headlines, the "blurring of fiction and reality may influence viewers' perceptions of the criminal justice system and criminal justice problems..." (2004:161). However, we appear to agree that the media plays an important role in framing, at the very least, the opinion of individuals. We tend to identify with characters, both real and fictional, that display traits that we have, sympathize with or resemble. In a study on the media coverage of the O.J. Simpson trial, Lisa Anderson (2001) wrote:

We chose a character with whom we identified from the characters the writers gave us-the battered woman, the innocent bystander, the football hero, the racist police officer, the ever-exasperated judge, the working-mother prosecutor, the dynamic, outspoken black defense lawyer. We created our own protagonists, making this real-life drama about much more than a murder; it became about America and the roles we all play within this society. Who any of these people are or were did not matter; we only came to know them from the performances so well-directed by news cameras. We may never learn anything about the identity of the murderer; but we might learn a great deal about ourselves and our culture by considering the presentation of the trial. (Anderson:42)

Whether the media has a direct or an indirect influence on attitudes and perceptions, it is clear that a relationship does exist. Given this, it is important to understand whether media representations of crime reflect the reality of criminal behaviors. This is especially true when we are examining race and social class since it is possible that the media can demonize poor and especially non-white individuals.

\section{Race and Class in Media Representations of Crime}

Our understanding of the portrayal of crime has remained fairly consistent over the years, but there is 
some evidence that, at least in the crime drama, the portrayal of race and social class is changing. Humphies (1981) argued that media representations of crime conform with publically held opinion. Fabianic makes the same argument in 1997 as do Cheatwood (2010) and Littlefield (2011) more than a decade later.

Historically, non-whites have been underrepresented in commercial media and when they were included they were more likely to be criminals or otherwise socially deviant. (Romer, Jamieson, and DeCoteau, 1998) They were also more likely to live in poor urban areas in substandard housing (Mastroa, and Robinson, 2000). However, this trend shifted and by the mid-90s, minority characters were visible in popular programming at rates equal to their distribution in "real-world" populations (Greenberg, and Brand, 1994). The programming that saw the most dramatic shift was the crime drama. Prior to the 1980s, when a non-white actor appeared in a crime drama, they were more often than not the criminal. This appeared to remain true for at least two programs in the early 2000s. In a study of the 2001 seasons of both NYPD Blue and Law and Order, Eschholz and colleagues (2004) found that non-whites were more often portrayed as criminals and were nearly twice as often to be shown handcuffed than white perpetrators.

All of these authors agree that misrepresentations of crime within the media drive public opinion which, in turn, drives public policy. So while the notion that crime, especially violent crime, is overrepresented remains consistent, the same argument may not apply to the consistent portrayal of non-whites as criminals. If public opinion drives entertainment, it is likely that the understanding of the bias in society may be reflected in fictional entertainment more than in news reporting, as individuals associated with the development and production reject overtly racist or biased programming. In fact, Potter and colleagues (1995) found that by the mid-90s non-whites were far less likely to portray criminals than their real-life counterparts and were less likely to be portrayed as violent or aggressive.

This representation of non-whites as non-criminally deviant did not hold true for reality programming or news coverage however. Mastroa and Robinson (2000) conducted a study of race, crime and programming over a two week time frame. This study included both fiction and non-fiction programs that were aired over every major network and cable network. Their study found that non-whites, specifically African Americans and Hispanics, were less likely to be portrayed as criminals in fiction programming. However, reality shows, like 'Cops', were far more likely to have white police officers and non-white criminals. They argued that while fictional portrayals were less likely to create fear of non-whites in public opinion, that the portrayal of non-whites in non-fiction has not changed and would still promote negative public opinion outcomes. This is consistent with earlier research. Sheley and Askins (1981) conducted a study of news programs and papers and found that non-white criminals (or suspected criminals) were more likely to be pictured in the news media. Likewise, Dixon and Linz (2011) and Cheliotis (2010) found that in news reports of crime, victims were more likely to be white and criminals were more likely to be African American. However, Schildkraut and Donley (2012) found that race and gender were not significant predictors of news reports of murder in the Baltimore area. Rather, the motivating factor for news coverage was whether the crime was local and the details of the crime. The significant predictors were age of victim (51+) and whether or not the murder was 'unusual'. Most murders in the Baltimore area involve guns, for example, so a drowning victim got more coverage because of the unusual nature of the murder.

Race gets more attention than social class in analyses of fictional representations of crime. When we examine social class, we find that criminals are more likely to be poor class. The focus of crime reports tends to be street crime as well. This finding has also been consistent. Randall and colleagues (1988) found that the focus of crime reports was 'common' rather than 'elite' crime. Some argue that when the crime is whitecollar, it not only goes unreported but the criminals receive preferential treatment in the court of public opinion. However, this may due in part to the general public's ability to 'connect' with the victim of a street crime more than the white collar crime. (Randall, LeeSammons and Hagner, 1988; Cheliotis, L. 2010). As Anderson discussed in her review of the O.J. Simpson trial (2001) we choose characters on television that we can identify with. This desire to identify and ability to connect with victims of street crimes is likely to be viewed as more profitable for television programming. The general population might be more inclined to tune in to programs like "CSI" or "Law and Order" because they can sympathize with the murder victims and their families. A program that focused on the most recent case of embezzlement might not draw as many viewers. 


\section{Interracial and Intraracial Crime in Public Opinion and Research}

Wilbanks (1985) argued that research supported the belief that the majority of violent crime was intraracial. $\mathrm{He}$ argued that this idea was so accepted in research that the incidence of interracial violent crime was often overlooked because it was accepted a priori that it was in the minority of crimes committed. His study provided groundbreaking evidence that most aspects of violent crime, with the notable exception of murder, were actually interracial. Furthermore he found that African Americans were more likely to choose a white victim for robbery, assault and rape. Wilbanks' work sparked more research on the relationship between the victim's race and the offender's race, with a focus on understanding why this relationship existed. More recent studies have found that African American's are 7.5 times more likely to commit an interracial crime than are whites which adds to the research interest in understanding why these differences exist as opposed to if they exist. (D'Alessio and Stolzenberg, 2009; Becker, 2007)

This topic is not being specifically addressed in most articles that examine race in media reports. We are told that the offender is more often non-white and that the victim is more often white, however there is little discussion of whether these individuals were engaged in inter- or intraracial crime. When the race dynamic is reported in the news media, there is often a strong public reaction. There have been several notable cases in recent history, the most recent of which is the Trayvon Martin case which resulted in a public outcry for justice within the African American community (Barry, Kovaleski, Roberson and Alvarez, 2012). Trayvon Martin was the 17 year old African American youth who was allegedly killed by George Zimmerman, a Neighborhood Watch participant in Mr. Martin's father's community. However, there was also a strong response in the white community, who felt that Mr. Zimmerman used acceptable force and acted in accordance with the "Stand your Ground" laws in Florida (Barry et al., 2012). When I conducted a brief Google search on this case it brought up $133,000,000$ hits. Upon reading the first several pages of citizen posts, these appeared to be divided between outraged citizens who decried racial profiling and outraged citizens who decried race being used as a factor in the discussion. It may be that the relationship between offender and victim race is intentionally underreported in the news media due to the public outcry that follows. However, more recent studies of crime dramas also have not discussed the portrayal of interracial vs. intraracial crime. There appears to be a "read between the lines approach" with offenders more likely to be non-white and victims more likely to be white which leaves us to draw the conclusion that most crime is interracial.

While the discussion of interracial crime may not be overt, there has been some discussion of how it is portrayed in fictional police series. De Bruin (2010) conducted a study of Dutch teens that examined how they responded to two popular police dramas. He found that the racial assumptions about victims and offenders were often intentionally misrepresented as an educational tool:

Prejudice is challenged more explicitly
through 'red herrings': non-white
characters are represented in a
stereotypical way, which leads viewers to
believe they are the culprit of the crime,
but by the end of the episode they turn out
to be innocent. (DeBruin:314)

He also found that teens responded favorably to both negative and positive stereotypes represented in crime dramas. They responded more favorably to "real" characters, those that resembled the characteristics that they saw in others in their own personal experiences. He also found that the teens were more likely to identify with the police in the shows, with their primary focus on solving the crime than on the aspects of the criminal activity or the characteristics of the individuals involved. Finally, he found that teens that were exposed to more diversity in their life experiences had better understandings of prejudiced stereotypes in the programs than did teens that lived in homogenous communities. The self-identification with the police and the tendency to prefer more realistic representations may provide evidence that the crime drama can, if fact, play an educational role at least with the young (DeBruin, 2010).

\section{Profit and Social Responsibility}

Whether the relationship is direct or indirect, as we understand the relationship between unrealistic media portrayal of crime and public fear, it seems reasonable that we would argue for social responsibility in programming, both fiction and non-fiction. Of course, we need to remember that the media, regardless of the forum, is driven by the market which is driven by public opinion. Therefore, both televised news shows and 
crime dramas are driven by the ratings. In a study of entertainment professionals, Klein (2010) found that those who create entertainment are aware of the educational opportunities that the media can provide and are sensitive to the need for educational programming. Programs will often deal with political arguments as a means of educational entertainment and news programs typically incorporate elements of entertainment as well as reporting. However, the role of education was not seen as the primary goal of the program. The focus was on ratings and profit. Educational topics that were considered successful were more likely to illustrate realistic experiences, such as popular reality shows that focused on health behaviors and illnesses or historical documentaries.

As stated above, De Bruin (2010) found that prejudiced attitudes were challenged and debunked in the crime dramas he analyzed. However, Klein (2010) argues that social issues that are covered in entertainment more often than not reflect the statusquo rather than posit any "unconventional" approaches to understanding social issues. Also, much of the educational material in both fiction and non-fiction may take the same delivery process so that it is not readily understood by the viewer. To complicate the matter further, viewers may often resist educational elements in entertainment because they are viewed as propaganda. (Klein, 2010; Delli Carpini and Williams, 1994)

As with our understanding of the representation of crime in the media, this argument has stayed fairly consistent over time. Welch and colleagues (1997) argued that the discourse in the media was driven by the needs of the dominant group and was designed to make them appear morally superior. They wrote:

Moreover, because such definitions are imposed early in the defining stage of the social construction of the crime news-by public officials whose credibility typically rests in their positions of power and prestige-these ideological perspectives command the field (Welch, et al. 475).

The nature of programming creates a non-recursive relationship between the public and the media. Out of necessity, the media takes a "give them what they want" approach to programming. This would seem to indicate that the misrepresentation of violence and crime in the media is at least, in part, due to public demand. We are left with a chicken and egg argument about the representation of violence and crime in the media which isn't new. Cheliotis (2010) observes:

Alas, rather than cultivating
communitarianism and deliberative
democracy, the media play upon public
fears by overstating the danger of criminal
victimisation, targeting weak and
marginalised swathes of the population,
criticising the authorities for laxity, calling
for more and harsher punitive measures,
and blocking or neutralising the imagery of
human suffering thereby caused.
(Cheliotis:178)

\section{SUMMARY AND STUDY RATIONALE}

Media representations of race and crime are topics that are still very much alive in current academic research and discourse. For the most part, studies agree that the news media over reports the incidence of violent crime and that this influences public opinion by creating a culture of fear (Reber and Chang, 2000; Gerbner and Gross, 1970 ;Klite, Bardwell and Salzman, 1997; Artwick and Gordon, 1998; Gilliam, 2000). Furthermore, this fear tends to be racially motivated as news reports continue to more often portray non-whites as criminals and whites as victims (Romer, Jamieson, and DeCoteau, 1998; Mastroa, and Robinson, 2000; Robinson, 2000) . Results are somewhat varied when entertainment media is discussed. Most studies discuss the overuse of violent crime in popular dramas. However, they also find that non-whites tend to be portrayed as characters more often in recent history and that they are less likely to be portrayed as criminals in these programs. These results do not extend to reality crime programs however. Reality shows follow the practices of the news media and are more likely to show non-white criminals and white police officers (Mastroa and Robinson, 2000; Dixon and Linz, 2011; Cheloitis, 2010. Inter- vs. Intraracial crime is not often discussed in more recent studies.

The importance of these programs to public opinion is open for debate. Some argue that these shows are a strong factor for creating public opinion and feeding a culture of fear. Others argue that the shows reflect public opinion and are responding to the marketability of violence and prejudiced perceptions. Still others find that while these shows do create and feed public opinion, that the overall effect is negligible or indirect. (Valentino, 1999; Reber and Chang, 2000; Robinson, 2000). 
Whether we argue that the effect of the media is direct or indirect, as a group, we appear to agree that the media representation of crime does affect society at large. Sparks (1992) argued that crime and punishment are always portrayed in society and that the portrayals actually reflect social struggles on public issues. Again, this points to a non-recursive relationship between the media and public opinion. Based on this understanding, we would expect to see a change in trends in the way that race and social class are portrayed in crime reports and crime drama. This would be due to an effort to reduce overt racism and classism in society, following changes in U.S. culture over the last fifty years.

This study addresses several questions that remain. Utilizing the first decade ${ }^{1}$ of Law and Order (19901999) will allow a discussion of change in representation over time within the context of one consistent program. This study was designed to determine if Law and Order supports the argument that criminals are more likely to be portrayed as lower class and non-white. This study also addressed several topics that are not specifically addressed in recent studies, such as inter- vs. intraracial representations of crime in fictional programming. Does fictional television programming, as evidenced in this show, reflect a realistic portrayal of the relationship of victim race and offender race? Does the program portray most offenders as coming from the poor classes? Finally, does the language that addressed race and social class as elements of crime challenge or reflect the status quo?

\section{METHODOLOGY}

Each episode from the first decade of Law and Order (1990-1999) was utilized in this study for a total of 225 episodes. Law and Order was chosen for several reasons. It is one of the longest running television crime dramas in history (1990-2011) with twenty seasons. The show has had several successful spin-offs as well, such as Law and Order: Special Victims Unit (in its $22^{\text {nd }}$ year) and Law and Order: Criminal Intent (10 years). If fact, it has also had a spinoff show in Great Britain; Law and Order: UK that has currently been airing for four years, which indicates that the program has international appeal. The format of the show has been relatively stable across the years and

\footnotetext{
${ }^{1}$ The first decade was used to avoid programming that was released following the September 11, 2001 attack on the World Trade Center.
}

allowed for an examination of how public acts influenced the nature of the show. Furthermore, it was unique in its approach when it first aired because it wed two popular fiction motifs; the police drama and the legal drama.

Each episode of Law and Order begins with a crime and the police search to identify a criminal. Within the first half of the episode, the District Attorney's office becomes involved and the episode ends in the court room. Given this, the show is likely to influence public opinion in regards to both crime and punishment. This study does not test the effect of Law and Order on public opinion. Rather, it examines the potential effect by exploring how the show illustrates the relationships between criminal deviance and justice and the personal characteristics of the individual players involved. Given the popularity of the show and the success of the spinoff series, it is reasonable to expect that this show would have a significant effect on public opinion as it pertains to crime and justice. It is also reasonable to assume that it addresses public opinions.

This paper incorporated both descriptive quantitative measures and qualitative assessments of themes throughout the decade. The descriptive measures were used to determine if the portrayals by race and social class of victim and perpetrators were consistent with expectations and/or had changed over the course of the decade. Also, they were compared to determine if crime was portrayed more often as intraor interracial and if these relationships were significant. Race and social class were recorded by observation for both the victim and the perpetrator for each episode. Missing values were used when it was impossible to determine the variable. For example, most episodes have a visible victim portrayed by an actor or actress that allowed me to determine the race of the individual. Occasionally, this would not be the case and the individual might be addressed as female or male, without any indication of race or social class. A second issue with coding presented itself when there were multiple victims or multiple perpetrators. Since this study was designed to examine the representation of race and class in the media, when this occurred I assigned the code for the socially marginalized member of the category. For example, if the perpetrators/victims were multiethnic, I classified the group in order of most socially marginalized with priority given first to "Hispanic" and second to "Black." I decided to use this rational, rather than recording both races because I was interested in comparing perpetrator race to victim race. Recording multiple 
races for one perpetrator would have confounded the analysis.

Social class presented a few more problems for coding. In most episodes, the class of the victim and perpetrator could be determined from either a discussion of social elements, such as connections or employment or from the lifestyle of the individual. For example, there might not be a discussion of income or employment of an individual, but they might be shown in a luxurious home or a clearly impoverished apartment. Most errors of determination were for the working and middle classes. In these cases, a missing value was assigned for social class. Likewise, when there were multiple victims or perpetrators, such as an episode that detailed a negligent club fire, a missing value was assigned. When more than one social class was evident, I decided to use the higher level as the categorization. This study was designed to determine, in part, if the majority of victims are portrayed as having resources and the majority of perpetrators are portrayed as poor or from the lower classes. Given this, assigning the higher value was determined to better fit the study design.

The final element of data collection for this study was a content analysis that assessed themes throughout the seasons. Notes were taken on each episode that included a brief description of the plot of the episode and, when relevant, the use of potential propaganda. In other words, episodes were analyzed to determine if there was a latent agenda within the program to either educate or perpetuate fear. The episode was considered educational if the characters engaged in a debate, especially on a controversial issue, that gave equal time to both sides. It was considered propagandized when only one side of the debate was covered or if there was no discussion of the debate but the outcome of the show could be interpreted as biased towards one side or the other. Finally, episodes were coded to determine if there was an overt discussion of social class as a factor that influences crime.

\section{RESULTS}

\section{Representation of Race and Crime}

More than $95 \%$ of the episodes during this decade had story lines that revolved around solving a murder. The overall majority of episodes across the decade portrayed both a white victim and perpetrator $(>80 \%$ in both categories). The notable exceptions were the first three seasons (1990-1992). Each of these seasons had the lowest victimization rate for whites (66.7, respectively.) Season three had the highest perpetrator rate for whites across the decade (95.5) and the lowest perpetrator rates for blacks $(0.0)$. For the most part, the first decade of Law and Order portrayed a majority of white victims and perpetrators. The majority of episodes featured white on white crime (83.4\%). Black on black crime accounted for only $4.3 \%$ of the episodes. Whites were more likely to be the perpetrators when interracial crime was portrayed. Twenty seven episodes had a non-white victim and in 23 , whites were the perpetrators (85\%). Minorities other than blacks were less likely to be portrayed in the episodes. Twenty three episodes featured a Hispanic victim or perpetrator. Of these episodes, $56 \%$ portrayed the Hispanic individual as the perpetrator. Only one episode featured a person of Middle Eastern descent and four episodes featured Asians. All five of these episodes portrayed these individuals as victims with white perpetrators (see Table 1).

These representations of race and crime are not fully representative of the national statistics for that decade. According to the United States Department of Justice (1997) blacks were seven times more likely to be murdered than were whites. Also during this time frame, blacks were eight times more likely than whites to commit homicide. While the number of victims and

Table 1: Percentages of Victim and Perpetrator Race in Sample

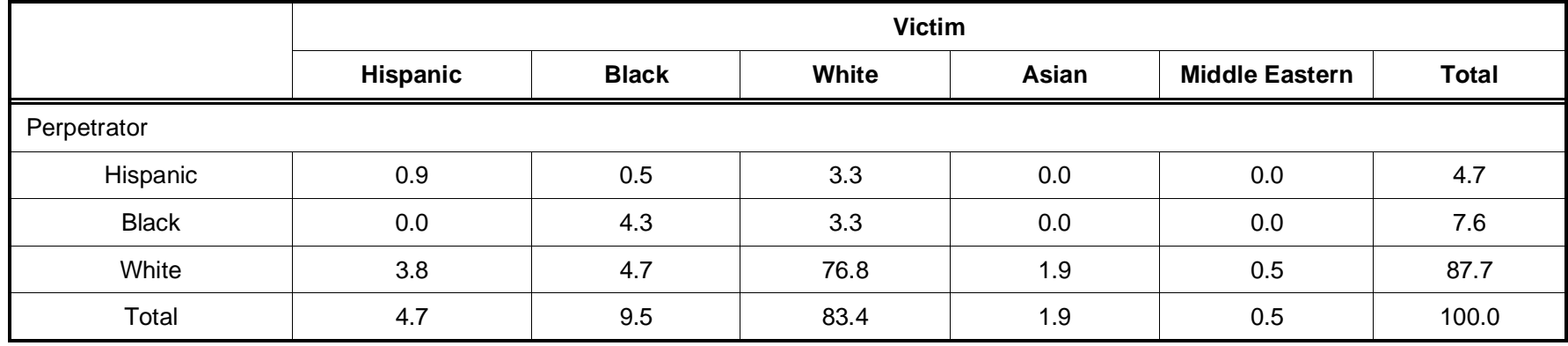

$X^{2}=50.23, p<.01$. 
perpetrators of crime were skewed towards whites, the portrayal of inter versus intraracial crime was fairly accurate when the crime was white on white; $83.4 \%$ of the episodes for white on white violent crime versus $85 \%$ in the national data. However the program did not reflect reality in the portrayal of black on black crime. The national data attributed $95 \%$ of black homicides to black on black crime. In nearly every case of interracial crime in the first decade of Law and Order, there was a white perpetrator and non-white victim. Overall, nonwhites accounted for 27 victims in the series and 23 were victimized by whites (85\%). Furthermore, black on black crime accounted for only $45 \%$ of the cases when the victim was black.

A Chi-square analysis showed that the relationship between victim's race and perpetrator's race was significant for this sample. In other words, whites were significantly more likely to be the perpetrator and victim in all cases.

\section{Representation of Social Class and Crime}

Victims and perpetrators of crime were primarily distributed across the Working, Middle and Upper classes for the decade (Victim percentages: 31.4, 26.8 and 35.6 respectively; Perpetrator percentages: 28.4 , 25.8. 39.8 respectively). Surprisingly the poor class accounted for only $5.7 \%$ of the victims across the decade and $6.7 \%$ of the perpetrators. Five years (199498) had no poor victims and 1994 and 1996 had no poor perpetrators. Only 1995 had greater than 10\% poor perpetrators (13.6\%). Eleven shows during the decade had a poor victim and of those, $73 \%$ showed the individual being preyed upon by someone with more resources (see Table 2).

Most episodes tended to portray crime as intraclass, rather than interclass. For example, the majority of upper class victims were preyed upon by upper class criminals, and so on. The distribution of victim class by perpetrator class was also significant $\left(x^{2}=109.2, p<\right.$ $.01)$. This is a clear change from past portrayals of criminals in fictional media. Not only were criminals more likely to be white in this series, but they were also more likely to be from classes with more resources than the poor class. Furthermore, these episodes were significantly more likely to portray the dominant or elite in society as preying on their own rather than being preyed upon by others.

\section{THEMATIC ANALYSIS}

I analyzed episodes to determine if the content of the shows appeared to be designed around educational topics of social importance in the portrayal of race and social class. In other words, was there evidence to support the conclusion that the overrepresentation of whites and the under-representation of the poor was an overt effort to 'right the wrongs' of prior generations' tendency to demonize the poor and non-whites in crime reports and portrayals? Length constraints prohibit an in depth discussion of every episode, however I provide representative examples here to illustrate how the program incorporated topics of race and class to provide both education and maintain the status quo, as past research suggests. (Klein, 2010; Delli Carpini and Williams, 1994) The results showed that Law and Order, at least during its first decade on the air, appeared to cover topics that were both socially relevant and current. Many of the episodes were loosely based on either actual criminal cases from the decade or topics that were socially relevant at the time. For example, episodes mirrored the Tawana Brawley case ${ }^{2}$, the Menendez brothers trial $^{3}$, sexual abuse by authorities within the Catholic church and the pro-choice debate, to name a few. When socially controversial topics were covered, the program consistently provided equal coverage of both sides of the debate, however there was also a tendency to support the status-quo. For example, several episodes dealt with the division over the death penalty in public opinion. The Assistant DA was a strong advocate for the death penalty in each of these episodes and his immediate subordinate was opposed. While both sides of the debate were covered equally, when the cases went to trial, the death penalty was typically imposed.

\section{Race}

Race was a prominent topic in only seven of the 225 episodes and in several of these, there was a crossover between race and social class. This may be due to the tendency to pull topics from current events. When race was a factor, the episodes dealt with either sensational true life cases or current controversies in public discourse. These episodes primarily focused on issues of justice for African Americans, problems with interracial dating and marriage, interracial adoption and affirmative action. When race was a topic of discussion,

\footnotetext{
${ }^{2}$ Tawana Brawley was an African American teenager who staged an interracial rape, including blaming several white police officers, to avoid discipline at home. This case resulted in widespread attention to the lack of police protection for people of color.

${ }^{3}$ The Menendez brothers were convicted of killing their parents and staging the murders to appear to be the result of a robbery. They alleged severe physical, mental and sexual abuse from their father as their defense.
} 
Table 2: Percentages of Victim and Perpetrator Class in Sample

\begin{tabular}{|c|c|c|c|c|c|}
\hline \multirow{2}{*}{ Perpetrator } & \multicolumn{5}{|c|}{ Victim } \\
\hline & Poor & Working Class & Middle Class & Upper Class & Total \\
\hline Poor & 1.5 & 1.0 & 3.1 & 1.0 & 6.7 \\
\hline Working Class & 0.5 & 19.1 & 6.2 & 2.6 & 28.4 \\
\hline Middle Class & 1.5 & 8.2 & 12.4 & 3.6 & 25.8 \\
\hline Upper Class & 2.6 & 3.1 & 5.2 & 28.4 & 39.2 \\
\hline Total & 5.7 & 31.4 & 26.8 & 35.6 & 100.0 \\
\hline
\end{tabular}

$X^{2}=109.2, p<.01$

the program appeared to attempt to provide a discussion of both sides of the debate, when relevant. For example, Good Girl (Season 7 Episode 3; 1996) dealt with the murder of an African American male college student by his white working class girlfriend. The frustrations of the African American community in getting justice were clearly represented in the dialog between McCoy, the white Assistant District Attorney and the family's attorney, an African American man named Baylor.

Baylor: It's been over a month Mr. McCoy. You haven't presented one witness to the Grand Jury or issued one subpoena.

McCoy: I'm sure you've explained to your clients Mr. Baylor; there's no need to rush to indict.

Baylor: You have a signed confession.

McCoy: We have a signed statement which came with a defense that we can't at this time rebut. [The girlfriend stated she killed the young man in selfdefense following a sexual assault.]

Baylor: Can't or won't?

McCoy: Don't be shy. Put your cards on the table.

Baylor: This white girl's lawyers are all over the news every other day. Mocking us. Calling their son a street hustler.

McCoy: I'm not trying this case in the media.

Baylor: You're not trying this case anywhere. You're saying that the killers of young black men have nothing to fear from the District Attorney.

McCoy: [to parents] I understand your frustration. But if we go to trial now, we'll lose. Simple as that.
Another example of the portrayal of race and justice and the inherent frustrations were presented in Out of the Half-Light (Season 1, episode 11, 1990.) This case was loosely based on the Tawana Brawley case with the Al Sharpton character being cast as an African American Congressman. The following scene is a discussion that takes place between Paul Robinette, an African American prosecutor and the Congressman after the young female's fraud is exposed.

Congressman: You look me in the eye and tell me this system is just. This system is equal.

Robinette: At times this system stinks. I know that as well as you do. But don't for one damn minute tell me that your self-aggrandizing and polarization is going to solve the problem. Don't tell me that tearing down a 200 year old justice system, no matter how flawed, is going to alter the consciousness of a society. We're past the separate drinking fountain stage. We're past legal discrimination. We're at the hearts and mind stage. But believe me, there's no quick fix. Your intentions might have been good but your execution stunk."

Regardless of the attempt to cover both sides of the issue, however, both examples also provide a resulting argument for supporting the status quo. Don't give in to frustration, but let the system work as it's designed.

Not every episode that dealt with race suggested maintaining the status quo however. "Custody" (Season Six, Episode 14; 1995) focused on transracial adoption and centered on a young African American mother who was charged with killing a social worker in order to get information on the current whereabouts of her toddler son, who she later kidnaps. Her son was placed for adoption with a white couple when she was found to be unfit due to drug addiction. This episode dealt with many of the legitimate issues that were being voiced by the African American community at the time. 
These issues included the child's loss of cultural ties to his community, the quickness to terminate the biological parents' rights and the inability for the biological parent to seek recourse within the law when they believed their rights were violated. These frustrations are clearly voiced in the courtroom dialogue. The defense attorney states;

"It [the system] stole Jamal Mays from his mother and placed him with a white family to be raised as a white child. Over the next few days l'm going to talk to you about racism in this country; about black children lost in white America. I'm going to show you how transracial adoption has become the code word for cultural genocide of African Americans. Now you won't hear this from them [white prosecution team]. They don't want to talk about race. Because they're good moral people they'll concede that there's racism in America. And oh what a shame that is. But they'll never concede it has any bearing on what happens in this courtroom or in the District Attorney's office. I know because I worked in that office for seven years. And they won't point the finger at the Child Health and Welfare system because one hand washes the other. They're all part of the same racist system." [The defense attorney is Paul Robinette, the prosecutor in seasons 1-2 who returns here].

The mother later takes the stand and argues "I'm the one that bore him into this world and I'm the one that can make him a strong black man. There's just no way that a white woman no matter how smart, how rich and how decent she is can do that for him." The camera pans frequently to the white adoptive mother who smiles at the woman and cries when she makes this statement, giving the impression of sympathy and a lack of animosity between the two mothers. The biological mother becomes less sympathetic however when she is asked if she would have taken her son if she had found him with a black couple. She sneers at the prosecutor and says "I had to take him back. They [the system] stole him from me." The jury comes back unable to return a verdict, willing to find the mother guilty of murder but unwilling to find her guilty of kidnapping which suggests that the jury agrees that transracial adoption is problematic.
While this episode challenges the assumption that a black child placed with a white family is always better off, it also portrays the young mother in a negative light. She is unmarried, a recovered drug addict, and by her own admission, violent to the point of committing a murder to right a perceived wrong. Similarly, in "Out of the Half Light", the young girl who stages a fraudulent rape does so to avoid discipline from her violent and abusive father. In "Good Girl", the young male victim is portrayed as violent and abusive as well. While these episodes challenge the injustices in the system, they also portray blacks as violent and dishonest and willing to manipulate the system for their own benefit, regardless of the cost to others or society at large.

\section{Social Class}

There were few episodes that dealt with social class as a primary theme. When they did however, they were equally divided between maintaining the status quo and challenging it. For example "Merger" (Season 10 Episode 4 ; 1999) deals with the murder of a wealthy teen that is addicted to drugs. The girl's parents and neighbors are less than willing to get involved in helping to solve the crime. As the show progresses, we learn that the dead teen's family is protecting the suspected killer, the son in the neighboring family, due to an impending marriage between the older siblings that will save the dead teen's family from bankruptcy. The show later reveals that the girl's maternal grandmother is the murderer. The murder was an attempt to keep the wealthy fiancé from discovering that the girl was actually the illegitimate daughter of her older 'sister'. Detectives Briscoe and Green discuss social class as an element of the case.

Briscoe: So far we got a bunch of rich folks running interference for their brat.

Green: You got a problem with rich people?

Briscoe: Given the fact that they're trying to buy their way out from under a murder charge.

Green: They're just trying to protect their kid. With or without a platinum card they're still parents.

Briscoe: Parents who have their name on a wing at the public library.

On the one hand, the dialogue between the detectives suggests that the wealthy are alternatively responsible caring parents or enablers. Also, Briscoe's character is represented as practicing reverse 
classism. His only justification for being against the parents' behavior is that they are wealthy. However, the episode ultimately demonizes the wealthy grandmother for valuing her social status more than the life of her grandchild.

Likewise "Cradle to Grave (Season 2 Episode 18; 1991) portrays the abuses of the haves against the have not's in society. This episode begins with a young African American male infant being discovered frozen to death and left in an ER waiting room. The investigation reveals that the young single mother left him alone at home because her sitter showed up late. The search for the woman begins at day cares where one worker explains that federal budget cuts have made providing infant care impossible. The woman goes on to criticize investing money in weapons rather than children. We learn that the neighbor who babysits was refused entry by the building owner who uses lack of maintenance and intimidation to force out the low income renters in the rent controlled building. This episode ends with the couple who own the building being convicted of reckless endangerment and manslaughter as the prosecutor argues "We live in a day where greed is glorified." Unlike the episodes that dealt specifically with race, this episode paints the young mother and babysitter in a sympathetic light. The mother is portrayed as making a bad decision by leaving her child alone for "only a few minutes" but not neglectful. She is grief stricken because her need to be on time to her low wage job conflicts with her desire to remain at home until her sitter arrives. The young Latina who babysits for her is also grief stricken and responsible. She spends several moments arguing with the superintendent and is led to believe that the woman and child are together. The wealthy building owners, both white, are portrayed as greedy thugs who put the value of a dollar above the value of all human life.

As with race, not every episode challenges the status quo for social class. "Rage" (Season 5 Episode 13 ; 1994) weds a discussion of both social class and race. An African American stockbroker kills his supervisor to hide fraud. This man is portrayed as the son of a successful working class family who believes in a minimalist lifestyle even though he has acquired significant wealth. Despite graduating from Harvard and having "all the right credentials" the company owner indicates that he was hired for "obvious reasons. We care very much about our appearance." As the case continues, it becomes clear that despite the man's credentials and appearance of success, he encounters racism and exclusion on the job. He uses a defense of "black rage", an overwhelming anger that develops after years of facing inherent racism in society. His attorney states "When a black man seeks justice in the white judicial system, his rights are usually violated." Much time is spent in a discussion of working class values with the man and his father. However, the most interesting facet of this episode is the man's criticism of affirmative action. He compares it to the Jim Crow laws and argues that it is an excuse to paint the African American as being unable to succeed in the white world. But it becomes apparent that he is not able to succeed which leads to fraud. From an analytical perspective, his lack of success defies explanation given his intelligence, work ethic and education. If he had been portrayed accurately, he should have been extremely successful without the need to result to fraud, having a BA and MBA from prestigious universities and a stellar work record prior to his employment with his current firm. While, on the one hand, the episode illustrates the need for affirmative action; the owner makes it clear that he would not have hired an African American man without the policy in place; on the other it underscores the African American perpetrator's arguments against the policy. This leads the viewer more likely to draw the conclusion that affirmative action does little more than its opponents argue; it provides opportunities to undeserving and incapable minorities.

This theme is also evident in "Haven" (Season 9, Episode 12; 1998). Here an African American counselor who works with disadvantaged Harlem males is killed because he is involved in a cheating scheme to help these young men gain acceptance to advantageous college programs. This episode portrays a young man driven to murder due to the stress of trying to achieve in a system that he is ill-prepared for. This episode brings into question preferential admissions to elite universities, the ability of poor youths to succeed without cheating and the corruption of the community leader who sells academic assistance and success. Again, the viewer is left to draw the conclusion that poor children cannot attain a quality college education without cheating and preferential admissions. The fact that these individuals are also black leaves us to draw the conclusion that this is especially true for black children and that when they fail they will become violent.

Two other episodes that focus on social class also included a discussion of lower working class students attempting to attain a level of education that is typically restricted to students with more resources. In "Pride 
and Joy" (Season 4, Episode $6 ; 1993$ ) the son of a building superintendent who is accepted to Princeton murders his father in a shame fueled rage because he is unable and unwilling to provide the trappings of success. When the boy is convicted, the ADA says "It's scary. A BA doesn't get rid of that kind of rage, not even if it's from Princeton". In "Wannabe" (Season 5, Episode 16; 1994) a working class boy who is on scholarship to an expensive prep school is expelled because the school is concerned that his values don't match that of the school. The boy steals his father's gun and, with the help of a wealthy classmate, kills the school board member responsible for his expulsion. The headmaster, in describing the boy says "Harrigan's a social experiment that failed. His gutter values contaminated the other students." Although one of the wealthy students is involved in the shooting, only the working class boy is prosecuted because his values will not allow him to accept a plea that requires him to name the wealthy boy as his accomplice. This episode gives the impression that while the working class boys are prone to violence, especially when they attempt social mobility, they are held to a higher ethical standard of friendship than the wealthy.

One interesting cultural note in these episodes is that both boys were Irish-American. When Logan and Briscoe are discussing the boy's expulsion in "Wannabe", Briscoe suggests that he "brought his mother's corned beef and cabbage to tea". Also in a scene where ADA McCoy, Detective Logan and the wealthy boy's father are meeting when the father states:

Father: It was Harrigan who put him up to it. He and his father, they're all alike with their Irish temper. They lose control..."

McCoy: So Harrigan did it because he's a Mick? Detective Logan is a Mick. I'm a Mick, sir. And if you don't shut up l'll lose control and throw you out of the room.

While both of the boys in these episodes are white and experience a homicidal rage when they attempt to step outside of their class expectations, the viewer is left to conclude that their ethnic identity might in some way be the motivating factor beyond their race. When his ethnicity is brought into question, McCoy also resorts to a threat of violence.

\section{DISCUSSION}

Overall, my study agrees with past research that examines the portrayal of non-whites as criminals in the crime drama. Potter and colleagues (1995) found that only ten percent of fictionalized crimes were committed by non-whites. This number was five times less than what occurred in 'real life'. When compared to the national statistics for the decade that the program was filmed, these results are even less realistic with non-whites being 8 times more likely to murder and 7 times more likely to be a murder victim than whites (United States Department of Justice, 1997).

Past research has examined the relationship between social class and victim portrayal in news reports, but has not really focused on this topic in the crime drama. Studies on the news have found that the violent criminals are likely to be portrayed as coming from the lower classes (Grover and Soothill, 1996). Randall and colleagues found that common crime or street crime was more likely to be covered in the media than elite or white collar crime (Randall, 1988). And Robinson argued that the media creates a mythology of the criminal as a poor non-white male (Robinson, 2000). My study somewhat contradicts these findings for the crime drama, at least when analyzing the first decade of Law and Order. The poor classes were not likely to be represented in this program. If fact, they accounted for less $10 \%$ of both the criminals and the victims in the series. However, when they were the criminals, they were likely to choose a victim from a higher social class (82\%). Finally they were slightly more likely to be portrayed as criminals than victims (55\%).

While several past studies included Law and Order episodes as part of their sampling framework amongst other shows, only Eschholz and colleagues (2004) focused on an entire season of Law and Order. My findings disagree somewhat with this study. They found a much higher percentage of black offenders than I did (16\% and $7.6 \%)$. However, they examined only one season rather than ten. My analysis showed that the rates of non-white offenders varied over the seasons, with the lowest percentage being zero and the highest being $33.3 \%$. This study utilized only the first ten years of Law and Order (1990-99) and Eschholz and colleagues used only the eleventh season (2000). In order to determine if the increase in 2000 is indicative of a major shift in the programs portrayal be race, it would be necessary to examine the remaining nine seasons of the program (2001-2011).

\section{Race, Social Class and the Dominant Discourse}

One major argument in past research on the media and crime is that the media plays to what the public 
wants (Cheliotis, 2010). Furthermore, the discourse in the media reflects the needs of the dominant group and is designed to make the dominant position appear more virtuous (Welch, 1997; Klein, 2010). Robinson (2000) argued that the media both constructs and reinforces a mythology about the criminal as a violent, poor, minority male. My study did not fully support this argument. Minorities were less likely to be portrayed as perpetrators across the decade and were also less likely to be portrayed as poor.

However, the analysis of the dialogue in the episodes that dealt specifically with race and/or social class as a topic provided mixed results. Regardless of their race, poor or working class individuals who attempted to become socially mobile were portrayed as undeserving or unable to succeed without artificial government support or charity. When these individuals were white, one of these episodes overtly blamed ethnicity and the Irish-American culture, while the other was more subtle. When the individuals were black, the discussion of race was more overt. All of the poor or working class perpetrators, regardless of their race, were portrayed as being violent, especially when they didn't "keep to their place" in the social hierarchy.

Most notable in these portrayals was the lvy League educated, accountant who gets hired due to affirmative action. There is no explanation for why this man did not succeed at his job. He was intelligent, experienced and educated in the field but still failed to produce. When he failed, he committed fraud and then murder to cover his fraud and his defense was 'black rage'. This episode appeared to support the dominant views that affirmative action merely promotes unqualified minorities over their more qualified white counterparts, especially since the man also joins this rhetoric and denounces the law as biased and prejudicial. The episode that dealt with preferential admissions to elite universities by race also had a negative outcome for those involved and seemed to support the argument that the media promotes a mythology of the violent, poor black male. We are led to believe that poor black men can only succeed academically and professionally when they cheat. Furthermore, both of these episodes illustrate the 'danger' that these affirmative action programs present to the law abiding population. Social promotion leads to stress, frustration and rage and this leads to acts of violence. While I can't fully confirm that Law and Order portrays the average criminal as a poor, violent minority, per Robinson's argument (2000), this study does support the argument that when the perpetrator is African American, he is portrayed as poor or working class and violent.

The two episodes that dealt specifically with racism within the criminal justice system also seemed to promote the status quo, and as with the affirmative action episode, the dominant discourse was repeated by an African American actor. Both episodes dealt with the African American community's inability to get fair treatment within the system and in both cases the main players were urged to work within the system and to be patient. Robinette argues that overt discrimination is a thing of the past and that we are at the "hearts and mind" stage. The message here is that the dominant culture is offended by overt actions to draw attention to the inadequacies of the system. The vocal politician is called "self-aggrandizing" and accused of polarizing the community. This discussion seems to argue that injustices in the system should be handled with subtlety and at the individual level rather than with a public decrying of injustice.

Only one episode appeared to challenge the dominant discourse on race, although it also reinforced the racial mythologies on violent crime. This episode dealt with transracial adoption and the perceived harm to a child that would be raised outside of his cultural traditions. It also addressed a very real concern that non-white parents are more likely to have their rights terminated with little recourse in the system for getting them back when they are rehabilitated. Despite the language that supported the non-dominant viewpoint, the child remains with his white adoptive parents since the mother is convicted of murder, however. So the outcome supports the adoption even though the discourse does not.

This study addressed another issue that has not been covered in past research. Studies have found that historically, non-whites have been portrayed as criminals by the media and that whites have been portrayed as victims (Gilliam, 2000; Romer, 1998; Mastroa, 2000). By the mid-90s this trend had shifted for the crime drama with non-whites being less likely to be portrayed as criminals than was true in real life (Potter, 1995). National data showed that intraracial crime was more prevalent than interracial crime for the decade of programming that I analyzed (United States Department of Justice, 1997). However, the overrepresentation of non-whites as criminals and the under-representation of their victimization remain consistent in the reality shows and news reports (Mastroa, 2000). This leaves the viewer to draw the 
conclusion that criminals are non-white and victims are white.

Another goal of my analysis was to determine if the myth that most crimes were interracial would be reinforced by the portrayal of criminals and victims across the decade. I found that whites were far more often shown as both criminal and perpetrator. Most of the episodes $(95 \%)$ dealt with murder or violent crime and both the victim and the offender were white in $85 \%$ of those episodes. Furthermore, when the victim was non-white the majority of the offenders were white $(85 \%)$. These results indicate that the program does not support the findings on racial differences in offender and victim in studies of print and televised news programs. It is impossible to determine the causes for this discrepancy without an in depth ethnography of the entertainment industry. However, it is likely that this reflects the sensationalism of headline grabbing news. As Eschholz noted in her study of Law and Order and NYPD Blue (2004) the program that was analyzed marketed itself as being realistic and pulling stories from the headlines. At least one study (Schildkraut, 2012) found that the most important motivator for news coverage of crime was the 'unusual' nature of the crime. It is possible that the majority of stories portrayed over the decade were 'unusual' and that the racial representations were a byproduct of that rather than a direct design to educate or challenge biased opinions.

\section{LIMITATIONS}

Most studies that examine race within the context of the crime drama use a random sample across several programs or compare multiple episodes of several programs. This analysis was limited to the first ten years of Law and Order. While this allowed me to determine if the program followed a consistent pattern of portrayals of race, class and crime, it may not represent the average program that was being viewed during the decade. Also, the programs reliance on headlines from the era for building a story may confound the interpretation of the data. On the one hand, the writers and producers may have made an active decision to present less biased accounts of race and class in crime portrayal. On the other, their use of sensational stories might mean that this is simply a byproduct of reality. It also might be evidence that there is more media and public interest when both the victim and the offender are white and/or from the upper classes. Finally, if studied in its entirety, the program might conform more to historical expectations. This argument could also be made about the entire Law and Order franchise, both nationally and internationally. Future studies should incorporate more of the franchise to determine if the first decade of the program is representative.

\section{CONCLUSION}

It is clear from the above data that the Law and Order program does not fully conform to expectations for race and class distributions in their presentation of victims and perpetrators. Whites were more often portrayed as both victim and victimizer and the poor were less likely to be portrayed as being involved in crime. It is also clear that the show attempts to use both socially relevant and socially responsible programming. However, the results are divided on whether the issues of the relationship between race, class and crime are covered in ways that educate the population or whether they support the status quo. Law and Order episodes are skewed towards whites in their portrayal of both victim and perpetrator with nearly $83 \%$ of victims being white and $85 \%$ of perpetrators being white. Likewise less than $10 \%$ of perpetrators were non-white. Story lines were often pulled from the headlines and were typically based on provocative or controversial cases, such as affirmative action. A further qualitative analysis of repetitive themes over the course of the decade's episodes would be useful in order to determine how often the show supports the status quo when topics other than race and class are the focus.

This paper limited its discussion to only the handful of episodes that dealt specifically with race and social class. When looking independently at distribution of race and social class across the first decade of Law and Order, it appears that efforts are being made to diversify the portrayal of non-whites and lower class individuals as the primary participants in criminal behavior. Whether this is intentional or merely a byproduct of 'borrowing' heavily from sensational headlines is impossible to determine. However, when we look closely at episodes that make race or social class a major element of the crime the results are less revolutionary in challenging preconceived beliefs in society. Arguments encourage African American's that are mistreated by the system to allow this flawed system to run its course. When the validity of the system is demonstrated to be inadequate, the jury is hung, leaving it to the viewer to decide who is right. Most of the episodes that deal with social class appear to have a latent message that individuals who fail to 
'stay in their place' are both inadequate and doomed to failure, as well as potential risks to the class they strive to join. In summary, the first decade of Law and Order shows more diversity in the criminal population by race and class than we would expect based on past research. However, educational topics are more likely to support the status quo in terms of race and class relations.

\section{REFERENCES}

Anderson, Lisa M. (2001) Presumed Guilty: I thought this was the Movie of the Week. The Black Scholar 25(4):40-42.

Artwick, Claudette, G. and Gordon, Margaret, T. (1998) Portrayal of U.S. Cities by Daily Newspapers. Newspaper Research Journal 19(1): 54-63.

Barry, Dan, Kovaleski, Serge. F., and Robertson, Campbell, and Alvarez, Lizette. (2012) Race, Tragedy and Outrage Collide after a Shot in Florida. New York Times, 4/1/2012. Retrieved from http://www.nytimes.com/2012/04/02/us/trayvon-martinshooting-prompts-a-review-of-ideals.html?ref=trayvonmartin \&_r $=0$

Becker, Sarah (2007) Race and Violent Offender Propensity: Does the Intraracial Nature of Violent Crime Persist on the Local Level? Justice Research and Policy 9(2):53-86. http://dx.doi.org/10.3818/JRP.9.2.2007.53

Boda, Zsolt and Szabó, Gabrielle (2011) The Media and Attitudes towards Crime and the Justice System: A Qualitative Approach. European Journal of Criminology 8(4):329-342. http://dx.doi.org/10.1177/1477370811411455

Cheatwood, Derral (2010) Images of Crime and Justice in Early Commercial Radio - 1932 to 1958. Criminal Justice Review 35(1):32-51.

http://dx.doi.org/10.1177/0734016809348358

Cheliotis, Leonidis K. (2010) The Ambivalent Consequences of Visibility: Crime and Prisons in the Mass Media. Crime, Media, Culture 6(2):169-184. http://dx.doi.org/10.1177/1741659010378629

D'Alessio, Stewart. J., and Stolzenberg, Lisa (2009) Racial Animosity and Interracial Crime. Criminology 47(1): 269-296. http://dx.doi.org/10.1111/j.1745-9125.2009.00145.x

De Bruin, Joost (2010) Young People and Police Series: A Multicultural Television Audience. Crime, Media and Culture 6(3): 309-328. http://dx.doi.org/10.1177/1741659010382331

Delli Carpini Michael X. and Williams Bruce (1994) 'Fictional' and 'non-fictional' television celebrates Earth Day: or, politics is comedy plus pretense. Cultural Studies 8(1): 74-98. http://dx.doi.org/10.1080/09502389400490051

Dixon, Travis L. and Linz, Daniel (2000) Over Representation and Under Representation of African Americans and Latinos as Lawbreakers on Television News. Journal of Communication 50 (2):131-154.

http://dx.doi.org/10.1111/j.1460-2466.2000.tb02845.x

Dixon, Travis L. and Linz, Daniel (2011) The Impact of Stereotypical vs Counter-stereotypical Media Exemplars on Racial Attitudes, Causal Attributions, and Support for Affirmative Action. Communication Research 38: 497-516. http://dx.doi.org/10.1177/0093650210384854

Eschholz, Sarah, Mallard, Matthew, and Flynn, Stacey (2004) Images of Prime Time Justice: A Content Analysis of "NYPD Blue" and "Law and Order". Journal of Criminal Justice and Popular Culture, 10(3):161-180.

Fabianic, David (1997) Television Dramas and Homicide Causation. Journal of Criminal Justice 25(3):195-203. http://dx.doi.org/10.1016/S0047-2352(97)00004-4
Feilzer, Martina (2009) The Importance of Telling a Good Story: An Experiment in Public Criminology. The Howard Journal 45(5):472-484

http://dx.doi.org/10.1111/j.1468-2311.2009.00589.x

Gerbner, George. (1970) Cultural Indicators: The Case of Violence in Television Drama. Annals of the American Academy of Political and Social Science. 388: 69-81. http://dx.doi.org/10.1177/000271627038800108

Gerbner, George and Gross, Larry (1976) Living with Television: The Violence Profile. Journal of Communication. 26(2): 173-199. http://dx.doi.org/10.1111/j.1460-2466.1976.tb01397.x

Gilliam, Franklin D. and Iyengar, Shanto (2000) Prime Suspects: The Influence of Local Television News on the Viewing Public. The American Journal of Political Science. 44(3):560-573. http://dx.doi.org/10.2307/2669264

Greenberg, Bradley S. and Brand, Jeffrey E. (1994) Minorities in the Mass Media: 1970s to 1990s. In Bryant, J. and Zillman, D. Media Effects: Advances in Theory and Research, pp 273314. Hillsdale, NJ.

Greer, Chris (2005) Crime and Media: Understanding the Connections. In Criminology, Oxford University Press.

Holbrook, R.Andrew and Hill, Timothy G. (2005) Agenda Setting and Priming in Primetime Television: Crime dramas and Political Cues. Political Communication 22: 277-295. http://dx.doi.org/10.1080/10584600591006519

Humphries, Drew (1981) Serious Crime, News Coverage and Ideology: A Content Analysis of Crime Coverage in a Metropolitan Paper. Crime and Delinquency 27(2): 191-205. http://dx.doi.org/10.1177/001112878102700202

Klein, Bethany (2011) Entertaining Ideas: Social Issues in Entertainment Television. Media, Culture and Society 33(6):905-921. http://dx.doi.org/10.1177/0163443711411008

Klite, Paul, Bardwell, Robert A., and Salzman, Jason (1997) Local TV News: Getting away with Murder. The Harvard International Journal of Press and Politics. 2(2): 102-112. http://dx.doi.org/10.1177/1081180X97002002009

Littlefield, Melissa M. (2011) Historicizing CSI and its Effect(s): The Real and the Representational in American Scientific Detective Fiction and Print News Media, 1902-1935. Crime, Media, Culture 7(2):133-148. http://dx.doi.org/10.1177/1741659011406700

Mason, Paul (2006) Lies, Distortion and What Doesn't Work: Monitoring Prison Stories in the British Media. Crime, Media, Culture 2(3):251-267. http://dx.doi.org/10.1177/1741659006069558

Mastroa, Dana E. and Robinson, Amanda L. (2000) Cops and Crooks: Images of Minorities on Primetime Television. Journal of Criminal Justice 28:385-396. http://dx.doi.org/10.1016/S0047-2352(00)00053-2

Meyer, John C. (1975) Newspaper Reporting of Crime and Justice: Analysis of an assumed difference. Journalism Quarterly 731-34. http://dx.doi.org/10.1177/107769907505200419

Potter, James W., Vaughan, Misha W., Warren, Ron, Howley, Kevin, A., and Hagemeyer, Jeremy C. (1995) How Real is the Portrayal of Aggression in Television Entertainment Programming? Journal of Broadcast Electronic Media 39:179-192. http://dx.doi.org/10.1080/08838159509364322

Robinson, Matthew (2000) The Construction and Reinforcement of Myths of Race and Crime. Journal of Contemporary Criminal Justice 16(2):133-156. http://dx.doi.org/10.1177/1043986200016002002

Randall, Donna .M., Lee-Sammons, Lynette and Hagner, Paul R. (1988) Common versus Elite Crime Coverage in Network News. Social Science Quarterly 69(4) 910-929. 
Reber, Bryan H. and Chang, Yuhmim (2000) Assessing Cultivation Theory and Public Health Model for Crime Reporting. Newspaper Research Journal 21(4): 99-112.

Romer, Daniel, Jamieson, Kathleen H., and DeCoteau, Nicole J. (1998) The Treatment of Persons of Color in Local Television News: Ethnic Blame Discourse or Realistic Group Conflict? Communication Research 15(3):286-305. http://dx.doi.org/10.1177/009365098025003002

Schildkraut, Jaclyn. and Donley, Amy M. (2012) Murder in Black: A Media Distortion Analysis of Homicides in Baltimore in 2010. Homicide Studies 16(2):175-196. http://dx.doi.org/10.1177/1088767912438712

Sheley, Joseph F. and Askins, Cindy D. (1981) Crime, Crime News and Crime Views. Public Opinion Quarterly. 45:492-506. http://dx.doi.org/10.1086/268683

Simmel, Georg (1908) How is Society Possible? In "Georg Simmel: On Individuality and Social Forms. Levine, D.N. (ed) The University of Chicago Press, Chicago, IL. 1971.

Sparks, Richard (1992) Television and the Drama of Crime: Moral Tales and the Place of Crime in Public Life. Buckingham, Open University Press.
Surette, Ray (1998) Media, Crime and Criminal Justice. Images and Realities. Belmont, CA: Wadworth.

Surette, Ray (2007) Media, Crime and Criminal Justice. Images and Realities. New York: Wadsworth.

Swisher, Keith (2010) Pro-Prosecution Judges: 'Tough on Crime', Soft on Strategy, Ripe for Disqualification. Arizona Law Review 52(2):317-393.

Valentino, Nicholas A. (1999) Crime News and the Priming of Racial Attitudes during Evaluations of the President. Public Opinion Quarterly 63: 293-320. http://dx.doi.org/10.1086/297722

Welch, Michael, Fenwick, Melissa and Roberts, Meredith. (1997) Primary Definitions of Crime and Moral Panic: A Content Analysis of Experts' Quotes in Feature Newspaper Articles on Crime. Journal of Research in Crime and Delinquency 34 (4): 474-494. http://dx.doi.org/10.1177/0022427897034004004

Wilbanks, William (1985) Is Violent Crime Intraracial? Crime and Delinquency 31(1):117-128. http://dx.doi.org/10.1177/0011128785031001007

DOI: http://dx.doi.org/10.6000/1929-4409.2013.02.23

(C) 2013 Patricia Case; Licensee Lifescience Global.

This is an open access article licensed under the terms of the Creative Commons Attribution Non-Commercial License (http://creativecommons.org/licenses/by-nc/3.0/) which permits unrestricted, non-commercial use, distribution and reproduction in any medium, provided the work is properly cited. 